\title{
The Relation Between Normal and Abnormal Develop- ment of the Embryo of the Frog (III), as Determined by Some Abnormal Forms of Development.
}

\author{
By \\ T. H. Morgan. \\ With Plates XXXI and XXXI. \\ Eingegangen am 25. April 1904.
}

The following observations and experiments were made for the most part during the spring of 1903 . Although the different points taken up under each heading are not closely connected, yet they all have a direct bearing on the general problem included in the title of the paper, which is the third of the series dealing with these questions. The eggs were in all cases those of Rana palustris.

\section{Abnormal and Irregular Forms of Cleavage.}

Several observers have already described cases in which the first cleavage of the frog's egg divides the egg into unequal parts. I wish to record here two extreme cases of this sort in which the relation of the first cleavage to the gray area was noted. The eggs were also isolated and found to give rise to normal embryos.

In the first case, Fig. 1, the first furrow extended from the top of the black hemisphere over towards the region of the gray area. The first two cells were, in consequence, very unequal in size; the smaller being almost entirely black, but containing at its lower end a little of the gray area. When next examined the egg was in the eight-cell stage, and had four small black cells and four large black and white cells, Fig. 2. There can be little doubt that the two cells, first formed, had divided twice each time into nearly equal parts. The dorsal lip of the blastopore appeared later on the gray side of 
the egg. It is clear, therefore, that the first furrow and the dorsal lip did not coincide in position, as is the rule for the normal egg, nevertheless a normal embryo developed.

Another egg, Fig. 3, did not divide quite so unequally. The second furrow came in at right angles to the first. The third furrows divided the small cells into unequal parts, Figs. 4, while the two large cells had begun to divide, when the observation was made, by nearly vertical furrows, Fig. 5. A normal embryo developed here also.

These two cases support the conclusion, first expressed by PrLÜGER, that the cleavage-form, as such, does not determine the position of the embryo on the egg. In the light of more recent results in experimental embryology it is becoming more evident that the distribution of the protoplasm is the factor that determines the position of the embryo on the egg and not the position of the planes of division. It is true that the cleavage planes often follow the lines of separation between the different protoplasmic areas, and hence appear at times to separate the egg into its constituent parts, but it has been found that the position of the cleavage planes can be shifted and the embryo may still follow the protoplasmic fields, rather than the position of the cleavage planes. It is, in fact, more probable that the position of the protoplasmic areas (by directing the spindle) influence the position of the planes of cleavage than that the planes of cleavage determine the location of the material of the embryo. This point will be further discussed below.

Two other unusual forms of cleavage were found in another bunch of eggs. The first of these is shown in Fig. 6, and in side view in Fig. 7. One clearage furrow, 1-1, divides the egg into equal parts. This I shall arbitrarily call the first furrow. Another furrow, 2-2 (arbitrarily called the second here), starts above in the black hemisphere, but very much to one side. It does not extend down far into the egg. The two large black cell also show a plane of cleavage, 3 (called here the third furrow), which is nearly horizontal. It, also, does not extend far into the egg. Sections were made of this egg in order to see if the nuclei would give any clue as to what the peculiarities of the cleavage were due. A comet-like line of pigment extends from the cell-wall in the upper hemisphere into one of the blastomeres and probably represents the path of entrance of one spermatozoon at least. In each of the large blastomeres, and in the region of the third eleavage, an elongated pigment 
band indicates the division of a nucleus. In the small blastomeres on the crescent side of the egg there is a faint indication of a nucleus (?) in each. The most plausible explanation of this condition is, I think, that two spermatozoa have entered the egg and brought about its irregular division. In the other egg, Figs. 8 and 9 , the first plane of cleavage, 1-1, is the only one that is completed. It divides the egg into nearly equal parts one of the halves containing all of the gray area. Each of the first two blastomeres appears to have two divisions in it, indicated by the letters 2-2, 2-2. Whether these appeared in succession, or whether, as seems to be the case, they appeared at the same time in each of the cells, can not now be determined. Sections of this egg show that nuclei (indicated by the balls of pigment) are present in all of the subdivisions of the egg. Near the top of the large blastomere there are two paths of pigment that appear to indicate that two spermatozoa have entered the egg. If this is the case the irregularities of the divisions are due here also to the presence of two spermatozoa in the egg.

These two cases, in which the abnormal cleavage is probably due to polyspermy, are entirely different, therefore from the first two cases deseribed above, and also different from the cases that have been recently described in a paper by BoRING and myself 1 ). Since the general questions connected with the variations in the cleavage that we described were not there discussed, I propose to give a further consideration to some of the results here.

We found in about $81 / 2$ per cent of cases, that the first cleavage plane came in at right angles to the median plane of the gray area, and therefore in the position of the second plane of the »normal " division. In eggs of this sort we found that the median plane of the embryo sometimes coincided with the first plane of cleavage, and sometimes with the plane of symmetry of the gray area, and in other eggs it lay between the two. The explanation of this difference is probably as follows: - It appears that the gray area is produced in the interval of time between the fertilization of the egg and the first division. It is probably produced as shown by Moszkowski by a rearrangement of the contents of the egg, - a streaming of the interior due to the action of gravity. When the first spindle is formed it becomes placed at right angles to what was the median plane of flow, so that the first plane of division will 
correspond approximately to the median plane of symmetry, i. e., it will divide the gray area symmetrically. The position that the spindle has assumed at right angles to the plane of symmetry of the protoplasm is, I assume, brought about by the elongation of the astrospheres at right angles to the plane of symmetry. The flow of the protoplasm has probably come to an end in the normal egg before the elongation of the spindle occurs, so that the spindle takes the position just described without being influenced directly by the movement. If, however, after the gray area has been formed, or while it is forming, the eggs should be turned (due to the bunch as a whole shifting its axis) the flowing of the protoplasm may begin again, and may so affect the nucleus that is assumes a new position before division. Hence the first plane of cleavage may appear in a different meridian of the egg.

From the usual position of the spindle in the normal egg it appears that the spindle becomes placed in a position at right angles to the plane of symmetry of the protoplasm. The only assumption that we can offer to account for this is that some sort of regulation exists in the egg that causes the asters at the poles of the spindle to elongate across the plane of symmetry, and this movement of the asters will cause the spindle to lie also across the symmetrical plane of the egg. On the other hand we have assumed that this regulation may be easily disturbed if streams are set up in the protoplasm at the time of or after the elongation of the spindle. That this is not an arbitrary assumption is shown by the experiments of PFLÜGER and of Bons on eggs turned into oblique or inverted positions. The flowing of the protoplasm that then occurs is known to carry the nucleus into a different part of the egg, and the position of the plane of division, that may come in while the protoplasm is still moving, shows that the position of the spindle is affected by the direction of the flow. It appears in some cases at least that this effect is such that the long axis of the spindle is in the direction of the axis of flow of the protoplasm. The spindle may be looked upon, under these conditions, as an elongated body floating in a more fluid substance. Such a body will tend to become placed with its long axis in the direction of the stream.

I believe we can profitably apply these suggestions to the type of eggs in which the first cleavage is at right angles to the plane of symmetry of the gray area. I interpret the position of the first plane of cleavage in these eggs as due to a secondary rotation of the proto- 
The Relation Between Normal and Abnormal Development etc. III. 511

plasm of the egg after the gray area has been formed. This rotation, as I have said, may suffice to carry the spindle into a new position; the rotation itself being due to a change in the position of the egg, which the egg has failed to meet by rotating on its axis, as usually takes place when the eggs are turned into a new position.

Now the median plane of the embryo appears to be determined by the symmetrical distribution of the protoplasm. In these eggs, in which the first plane of cleavage comes in at right angles to the normal position, there will tend to be two planes of symmetry in the protoplasm, namely, the one first formed by the gray area, and the new one due to the secondary rotation of the contents of the egg. Whichever of these two exerts the stronger influence will determine the median plane of symmetry of the embryo. In some cases it will be the first, in others the second, and in still others the median plane will come to lie between the two. Hence the median plane of these embryos should be expected to coincide sometimes with the median plane of the gray area, and sometimes with the first plane of cleavage (i. e., at right angles to the gray area), and at other times to lie between the two. This is what we actually found to occur. Thus the same hypothesis that explains the shifting of the spindle and the abnormal position of the first plane of clearage will account for the change that sometimes, but not always, takes place in the position of the median plane of the body without supposing that the two are related as cause and effect. The connection lies deeper, namely, in the secondary change in position of the protoplasm that carries the spindle into a new position on the one hand, and produces a new plane of symmetry on the others, the latter change having a greater or less influence on the position of the median plane of the embryo.

It was also pointed ont by Borisg and myself that the third planes of cleavage are sometimes vertical instead of horizontal, and we found that this occurred most often on the side of the egg containing the gray area. In one bunch, in particular, a large number of such cases occurred. The explanation of these facts is probably as follows. The bunches of eggs were brought into the laboratory sometimes soon after they had been laid and before the jelly had swollen to any great extent. The bunches were often placed in shallow dishes. Under these circumstances compression of the eggs would almost certainly take place from above downwards, and this would affect the position of the clearage planes, as Borx and Hertwio 
have clearly shown. Furthermore the gray side of the egg is the side that is nearer the top of the egg than is any other part of the dark hemisphere, hence the vertical compression would be most likely to be shown on this side, and therefore the more frequent occurrence of the vertical cleavages in this region.

Pflüger in 1883 concluded that the spindle in the compressed egg would take the position of least resistance. HERTwig later modified this »rule* so that it read; - the spindle assumes the position of the greatest protoplasmic mass. Numerous exceptions have been found to this statement. In the case of the sea-urchins egg I pointed out ${ }^{1)}$ that this rule does not apply to the three-fold type of cleavage, and that in these the second planes of eleavage are clearly determined by a relation to preformed areas in the protoplasm. We are justified I believe in extending this conclusion to other, and perhaps to all cases, in the following sense. The position of the spindle itself is actually determined by movements of the protoplasm as admirably shown by Conkuin's recent observations on the egg of Crepidula. These movements of the protoplasm are in turn determined probably by the condition of the protoplasm in each cell as a result of which at certain times currents are set up, and it is these that carry the spindle into position. How far the basis of this arrangement depends on the structure of the protoplasm, and how far purely on a difference in composition of different regions can not at present be determined. Both factors may enter into the problem. The differential divisions of the protoplasm that so often occur may be cansed by the flow of the material, and as a consequence determine the position of the spindle. Thus there must be a finely adjusted set of conditions in the protoplasm that regulate the position of the spindle and the consequent position of the cleavage planes, but this regulation may be little more than the outcome of physical and chemical forces in the widest sense of the terms. Any attempt to refer the position of all spindles to a single factor as PFLÜGER and Hertwig have attempted to do, is almost certain to fail, for, in different cells the conditions that determine the direction of the flow of the substances that give direction to the spindle may be of very different kinds.

1) This Archiv. 1895. II. p. 75 . 
The Relation Between Normal and Abnormal Development etc. III. 513

\section{Is Gravity Essential for the Formation of the Plane of Bilateral Symmetry in the Frog's Egg?}

I do not propose to consider here that side of this question that has been discussed by Roux and by Schultze, but only the recent experimental evidence, in regard to the action of gravity, brought forward by Kathariner ('02), Morgan ('02) and Moszkowski ('02, '03). Furthermore I shall confine my discussion to certain questions raised by Moszkowskx in his last paper, in which he brings forward certain evidence which he believes controverts the interpretation that KATHARINER and I have given to our results. It will not be difficult to show, I believe, that MoszkowskI has failed to substantiate his elaim.

The evidence that Moszkowski brings forward to show that the experiments of KATHARINER and myself are inconclusive is two-fold. In the first place he claims that in our experiment a centrifugal force has been substituted for that of gravity, and has been the factor that has determined the median plane of the embryo. Now this assumption implies that the eggs must have rotated for some little time in the same plane, and this may actually occur, MoszkowskI claims, in bunches of frog's eggs rotating in a whirl of water. I do not question that this might happen, and presumeably did happen in Moszkowski's experiments. Whether it did, or did not, in KATHARINER's experiment, I will not pretent to say, but it seems to me improbable that so acute an observer could have overlooked so obvious an objection. In my own case I can state that I paid attention to this point and observed that the eggs did not rotate for any length of time in the same plane. The eggs of the toad are laid in strings, not in bunches as are the frog's eggs. These strings were cut up into short pieces of varying lengths. The rotation of these strings in the whirl of water was irregular in the extreme, and resembled a mass of living reptiles crawling in and out of the mass so that the individual eggs were carried through most complex and ever changing revolutions. I closely watched individual eggs and saw that they were constantly changing the plane of rotation as they slowly revolved in the water.

In the second place Moszkowski states that by turning on the water so that a strong current was produced he got abnormal development (protruding yolk for instance), which he says was due to centrifugalizing the eggs. Now this is a question with which I am 
especially familiar. Until Moszkowski states how many revolutions his eggs made in a minute, and their distance from the center of revolution, it will not be possible to determine whether or not his results are in reality due to a centrifngal force. I may recall that I have found that the eggs of Rana palustris may be rotated at the rate of 140 revolutions per minute at a distance of from $71 / 2$ to $191 / 2$ inches from the axis of rotation without eausing them to develop at all abnormally. It would be interesting to know if Moszkowskr rotated his eggs as rapidly as this, and if he did, the rate is so enormously greater than that which I ased for the toad's eggs that it is quite inconceivable that the two results can in any way be compared. It is no less important to remember that this form of abnormality, which Moszkowski says is due to centrifugalizing the eggs, occurs whenever the yolk cells are injured in any way as I have shown a number of different times. Rough handling, or perhaps even irregular shaking, if sufficiently violent, might produce exactly the same result as a strong centrifugal force. Therefore while it is perfectly possible that Moszkowski's abnormal embryos may have been due to the centrifugal force, the fact that this is the case is not sufficiently shown by the evidence that he has given.

To return to my own experiments with the toad's egg. That the results here were not due to the centrifugal force is shown I believe first by the irregularity of the rotation (as stated above), second by the entire absence of the gray area, or of a similar appearance on the eggs as they developed. Moszkowski overlooks the fact that $I$ took a few eggs out at intervals and examined them for this very point. Third that the development was normal in all respects and showed in no way that the eggs had been centrifugalized. The first and the second point suffice, however, to establish the conclusion that I drew from the experiments.

Finally it seems to me that while Moszkowsk has brought forward strong evidence to show that gravity is the most important factor under normal conditions in determining the arrangement of the protoplasm and in locating, in consequence, the median plane of the embryo, - (a further analysis of this relation I have attempted to give in the preceeding section for certain abnormal cases, - - yet it appears to me that he has arbitrarily assumed that gravity is the only factor that can produce this result in the frog's egg. In other eggs we have strong evidence to show that gravity plays no part 
The Relation Between Normal and Abnormal Development etc. III. 515

in the determination of the median plane of the embryo, and in these cases other factors must assume this function.

Now while I am willing to admit that gravity may play an important role in the frog's egg, it does not follow that, when the action of gravity is excluded, the egg may not have other means of determining the middle plane of the embryo. In fact, we do not have to look far to find other factors that might produce this result. The entrance of the spermatozoon may, as claimed by Roux, be a factor, if in no other way than as the outcome of the apposition of the two pronuclei and the position assumed by the asters in the plane of apposition, which will give a plane of bilateral symmetry that coincides in position with the point of entrance of the spermatozoon. Whether or not Roux's experiment of localized fertilization really establishes the conclusion that he has drawn from it, is a point that future experiments must decide.

The egg is at first attached to the wall of the ovary by one side, and it is not impossible that the point of attachment may, through a possible influence on the distribution of materials, produce a bilateral condition, or at least be an influence that may become a factor, if stronger influences are eliminated.

For these, and for other reasons that I need not go into here, I still believe that the evidence in favour of the view that the toad's egg, and probably also the frog's egg, can develop normally when the action of gravity in one plane is removed (and is not replaced by a centrifugal force) is valid.

\section{The Effect of Killing One of the First Two Blastomeres Before the Cleavage is Completed.}

Roux's experiment of sticking one of the first two blastomeres has lead to so much controversy that it may not seem surperfluous to describe an experiment in which a variation of this method led to an unusually definite result.

The question suggested itself: - what will occur if an egg is stuck at the time when the first furrow has just appeared? Will the division be stopped? If so and if at the same time one of the first two nuclei should be killed, or injured, there might result a whole egg containing the nucleus of only one of the first two blastomeres. Under such circumstances the development of the egg might give some points of interest. As a matter of fact it was found, as 
has been more fully described in my paper with Miss Torecle, that the first cleavage generally completes itself, so that the main purpose of the experiment can not be attained in this way. Indirectly, somewhat the same result is at times obtained by the breaking down of the cell-wall between the first two cells. If, however, the pucleus of the injured cell is not killed, as is nearly always the case, it may continue to divide and supply the injured half of the egg with the nuclei around which cell-walls may subsequently be formed, and this half become added to that of the uninjured half. In one egg, stuck at the time of appearence of the first furrow, the injury was so severe that the nucleus was seriously injured and failed to supply the injured half with nuclei. It divided very irregularly, and only a very few times, and the resulting nuclei remained near the place of injury. They did not become the centers of cell-formation. It was also evident that the part that developed was less in volume than half of the egg, which was due, most probably, to the cell-wall between the blastomeres breaking down so that the protoplasm of the lower part of the blastomere became continuous with that of the injured side, and failed to become supplied with nuclei in the later stages of development. Possibly in this case the cell-wall between the first two blastomeres had not completed itself which would lead to practically the same conditions in the egg as though it had first formed and then broken down.

A surface view of the egg, at the time when the embryo appeared, is shown in Fig. 16. A small shalf-embryo " is present on the uninjured side along the line of union with the injured half. The embryo appears to be somewhat less in size than a half-embryo, and this is due, no doubt, to loss of material from the uninjured side. The half medullary plate that is seen in the figure is somewhat broader at its anterior end where it is arched over to some extent by the yolk of the injured side. It is a point of interest to note that the medullary plate lies on that side of the egg that is opposite to the upper injured hemisphere of the other blastomere, which means that the embryo has formed over the yolk hemisphere of the egg. The egg was cut into cross-sections, three of which are shown in Figs. $G, H, I$. The first of these is through the anterior end of the medullary plate. This appears (above in the figure) as a nearly bilaterally symmetrical structure, lacking a little on the inner side. In sections further forward, however, the medullary plate becomes quite bilaterally symmetrical. Beneath the medullary plate lies the 
The Relation Between Normal and Abnormal Development etc. III. 517

mesoderm, extending as a thick sheet over one side while on the other, although it extends over the middle line, it is much less developed and does not continue downwards along the inner side at all. In the middle of the yolk the small opening of the archenteron is present. The outer surface of the embryo is covered by ectoderm, which in this section extends on the inner side between the embryo and the injured half.

The injured part of the egg, as shown in this same section, contains a few irregular and abnormal nuclei especially in the region near the point of injury. The protoplasm is much racuolated and may be dead in some places.

Passing along the series of sections towards the middle of the embryo, the ectoderm over the inner side is found to become thinner, and finally to come to an end over this side, as in Fig. $H$. The archenteron extends towards the inner side and opens out as shown in this figure. It is important to note that its roof is bounded by yolk-cells (endoderm), and that these are continuous near the opening with smaller cells, which are exactly like the mesodermal cells that lie on their inner side. Further out, along the upper, inner wall, the small cells grade off into the ectoderm, which still further is thickened to form the half-medullary fold. The notochord lies on the left side (in the figure) of the medullary plate, and is nearly surrounded by mesoderm from which it appears to have been cut off. It lies in the region where the ectoderm and the mesoderm of the of the surface become continuous. The mesoderm extends over the entire right side of the section, and is differentiating below from the yolk-cells.

Passing to sections further posteriorly we find that the arehenteron extends much farther into the yolk, even more extensively in some of the sections than shown in Fig. $I$. The ectoderm of the medullary plate extends further over on the inner side, and finally (posterior to Fig. I) the medullary plate is nearly bilaterally symmetrical again. In these posterior sections the notochord, as such, can not be found, because, no doubt, it becomes merged into the mesoderm in this region of the embryo. The surface ectoderm has apparently met with an obstacle on the lower side and its cells are heaped up there. The yolk cells on the inner side are looser than in the more anterior regions, and, here and there, seem to be imbedded in the yolk that is continuous with that of the injured part; but the cells are always near, or are directly continuous with, the 
yolk-cells of the embryo, and there can be no doubt that their nuclei have originated in the uninjured side.

This series of sections is instructive in many ways, and I wish to point out here, as briefly as possible, some of the more interesting questions that are involved, in the formation of an embryo of this kind.

If an egg in which one of the first two blastomeres has been stuck is kept under observation at the time when the dorsal lip of the blastopore first appears, (and the same is true for an egg stuck at the time when the first furrow has just come in), it will be found that the dorsal lip develops as a small crescent on the side of the egg near the line between the injured and the uninjured halves. It then begins to extend around one side of the egg to form the lateral lip as shown in Figs. 13, 14, 15, and at the same time the dorsal lip advances backwards over the surface of the yolk. The lateral lip has begun meanwhile to roll over the yolk also, and the ventral lip, that has now appeared, extends forwards for a short distance. In other words the uninjured half follows the same method of development as half of the normal egg would do. The open side of the archenteron represents the edge of the lateral lip of the blastopore.

The anterior end of the medullary plate of the frog-embryo is laid down in the undivided material in front of the first position of the dorsal lip of the blastopore, and hence on that part of the egg. not involved in the blastoporic overgrowth. It has been noted that the medullary plate in this half-embryo, especially at its anterior end, is a whole structure of reduced size, and not a half. This peculiarity of these half-embryos has also been noticed by Roux, but $I$ think its importance has not been fully appreciated, for there is no evidence that it is due to an early postgeneration of the missing (?) half. As far as I have been able to determine, the anterior end of the medullary plate is laid down at once as a whole structure, and not as a half that completes itself on one side; hence I can see no advantage in calling the process one of postgeneration, since the half is no more postgenerated than is the whole embryo that develops from the isolated blastomere of the sea-urchin's egg. In both cases, no doubt, some change takes place, so that the middle line becomes formed some distance from the inner edge, but this involves, I think, a different conception of the process from that which supposes the half of the whole structure is first laid down, 
and new cells are then thrown across, as it were, to the other side to duplicate the half-structure that was first formed. It is this latter process, to which Roux applies the term postgeneration. My own idea of what takes place involves the assumption of axial readjustment of material that is so little predisposed in one direction (halfstructure) that its relations may be readjusted in response to the form of the developing part.

In the middle regions of this embryo the medullary plate is a half-structure, or at most a little more than half. The notochord, although rounded and appearing therefore as a smaller, whole structure, lies on the inner side of the medullary plate, and is, therefore, in the position of a half-structure. It lies just beneath the surface, and is, in part, surrounded by mesoderm. The surface cells over the notochord show a gradation between the ecto- and mes-endoderm. These cells, as well as those that lie further along over the inner surface of this region, call for special notice. It is this part of the surface that is rolled over in the normal embryo to form the roof of the archenteron. The cells in this region are those just outside of the lateral lips of the blastopore, and normally are brought together to unite in the advancing dorsal lip of the blastopore. These are superficial cells that lie at first outside of the rim of the blastopore, but whether, therefore, we shall call them ectoderm or endoderm is, I think, entirely a matter of definition. If we determine to call them ectoderm, then we must conclude that part of the cells of the dorsal roof of the archenteron are at first ectodermal. It has been shown by Schwink and by KING that some of the cells of the roof of the archenteron are added to the notochord and to the mesoderm. Whether the dorsal wall, after this process has taken place, becomes purely endodermal, or whether some of the ectodermal cells may remain, can not be definitely stated. The distinction is perhaps largely artificial, for, in the lips of the blastopore, the ecto-, meso-, and endoderm are so closely united that it is probable that all the cells of this part have the potentialities at first of all three layers. Thus the notochord may be ascribed to the ectoderm, or to the mesoderm, or to the endoderm, at will, and it may be a matter of indifference to which layer we ascribe it, since the cells of these layers in the part of the embryo from which the notochord develops may all have the potentiality of producing this structure should they happen to get into the part from which the notochord is formed.

There is another point shown by this half-embryo that calls for 
a brief mention. The roof and the floor of the half-archenteron are formed from the yolk-cells, and the archenteron is produced here not by the rolling in of the edge, although this also takes place, but by the yolk-cells withdrawing and opening out. This part of the archenteron corresponds to the lateral portion of the archenteron of the normal embryo, which, I believe, is also formed by the withdrawal, or pulling in of the yolk-cells along the lateral lips of the blastopore. It is also probable that the same process occurs at the dorsal lip of the blastopore, as claimed by Assheron (though not so extensively, I believe, as he supposes). It is, of course, hazardous to argue from the conditions in the half-embryo to the normal development, but in the two cases the processes have every appearance of being the same, and in the half-embryo the conditions are such that there can be only one interpretation as to how the result has been attained; hence it appears to me not unreasonable to extend cautiously the same interpretation to the normal embryo where the result is more obscured by other conditions.

Finally I would recall that the half-embryo in this case is less than half in volume; due apparently to the loss of yolk material from the uninjured blastomere. This seems to have occured in the yolkregion of the more posterior part or the embryo, so that the equatorial zone from which the embryonic material is mainly derived has lost relatively less. The extent to which the yolk becomes nucleated from the nuclei derived from the uninjured half will determine how much of it becomes cellulated. In this particular case the nuclei do not appear to have extended over into the injured portion, although in consequence of the continuity of the yolk in this region the nucleazation might, as far as we can see, have been more extensive. As soon however as the protoplasm becomes broken up into cells around these nuclei, further nucleazation will come to an end, and this is what actually seems to take place in eggs of this sort. From this point of view the in-wandering of nuclei from the uninjured into the injured half, as Rocx claims to take place, is not likely to occur after the protoplasm has once become broken up into cells.

There is a question of theoretical interest in connection with the postgeneration of the injured blastomere which brings to light a difficulty of fundamental importance. If the shalf-embryo lies in large part over the lower hemisphere, as Roux believes, then there is opposed to the "open* side of the half-embryo the large yolk-cells of the lower hemisphere, as shown in Figs. 13, 14, 15. How is it 
possible that this material can be transformed into the dorsal side of the postgenerated "half", even under an influence emanating from the developed half, as Roux supposes. It must be remembered that the material to form the embryo proper is carried downwards by the overgrowth of the dorsal and lateral lips of the blastopore and has an origin relatively high up on the egg. The yolk-cells of the lower hemisphere form the floor of the archenteron, and are removed by half the diameter of the egg from those yolk-cells that form the mesoderm of the embryo. Hence it seems to me, in the light of recent advances, highly improbable that Roux's account of this process can be correct.

Closely connected with this question there is another, which, I believe, has not been sufficiently considered. According to Roux the characteristic process of blastoporic overgrowth, by means of which the material of the embryo is carried over the lower pole, is ommitted in the postgeneration of the injured half. For several reasons this does not appear to me to be possible. If, on the contrary, we suppose that the injury has only sufficed to delay the development of the injured half, is it possible that the uninjured half may first complete its gastrulation, and then the delayed half pass through the same process? There is no evidence that this occurs. If it did so, it would, no doubt, have been observed. Is it possible then that the development of the uninjured half is held back until the process of gastrulation can go on simultaneously in both halves? This may sometimes occur, but gives rise to spina bifida embryos, or even to normal embryos if the yolk has not been much injured. It does not appear that the "postgeneration " that Roux describes takes place by either of these two processes. There remains another possibility. The material for the middle and for the posterior regions of the body may be supposed to grow backwards from the head region of the half-embryo, i. e., the material of the injured half that lies at the side of the half(?)-head may be imagined to extend backwards in somewhat the same way as the dorsal lip extends backwards, without, however, an actual process of gastrulation taking place. It seems to me that we also lack evidence to establish this view. From the proceeding analysis it appears improbable that the material of the injured half can be used to replace the missing half-embryo unless it passes through a regular process of gastrulation. The half-embryo can at most only partially complete itself by a sort of lateral regeneration (involving to some extent the process of morphallaxis) of its 
own tissues. This view seems to me the most plausible one in the light of the experiments that have been so far carried out.

\section{The Size of the Cells of the Embryo, and the Size of the Egg.}

The eggs laid by each individual frog are usually all of about the same size within rather close limits. This size is often variable for different individuals of the same species. Every embryologist must, however, have found occasionally bunches of eggs in which smaller eggs than the rest of the batch are present. There is an interesting theoretical question connected with these small eggs, to which I have already called attention ${ }^{1)}$. I described some cases, in which small eggs of the toad were found that contained only onehalf of the volume of the normal eggs, and which, therefore, were equivalent in volume to one of the first two blastomeres. During last spring I found in one bunch of frog's eggs a few eggs that were so small that they at once arrested my attention. Measurements of these eggs showed that some of them contained no more than half of the volume of the other eggs of the same bunch. The following figures give the measurements of some of the small, dwarf eggs, and, for comparision, the measurements of some of the normal eggs.

\begin{tabular}{lll} 
Normal Eggs & \multicolumn{2}{c}{ Dwarf Eggs } \\
$50 \times 53$ & $37 \times 39$ & $42 \times 45$ \\
$52 \times 53$ & $40 \times 42$ & $43 \times 43$ \\
$50 \times 52$ & $42 \times 42$ & $44 \times 45$ \\
$49 \times 52$ & $44 \times 44$ & $42 \times 44$ \\
$49 \times 51$ & $44 \times 47$ & $42 \times 43$ \\
$50 \times 53$ & $40 \times 42$ & $45 \times 46$ \\
$50 \times 50$ & $44 \times 46$ &
\end{tabular}

If the cubes of the diameters of the dwarf eggs be compared with those of the full-sized eggs, the volumes will be found to be as 1 to 2. The small eggs were isolated and produced normal embryos, also of reduced size. These were preserved at different stages along with the normal eggs, and, later, sections were made of both kinds, always carrying one of the small eggs and one of the large eggs through the same solutions, etc., and using only these for comparison. Camera drawings were then made of cells from 
The Relation Between Normal and Abnormal Development etc. III. 523

corresponding regions of the two embryos of each pair, and the drawings compared.

Before speaking of the results there are a few points in regard to the origin of these dwarf eggs and their mode of cleavage that must be described. If the ovary of a frog be examined during the winter the full-sized eggs are found hanging from the walls of the ovary into the central cavity. In addition to these there are other eggs of all sizes, especially very small ones, that will become the ripe eggs of the following year. The dwarf eggs appear to have been some of the eggs that had not quite reached maturity (not the very smallest just spoken of). The pigment in these immature eggs is not so deep, nor so extensively developed, as it is in the large eggs. One of the most evident characteristics of the dwarf eggs also is their light color. It seems to me, therefore, probable that these eggs correspond to the small eggs of the ovary that have been accidentally set free, possibly because they were large enough to "ripen* at the time when this process occurred in the ordinary eggs.

In several cases I followed the process of cleavage of the dwarf eggs. It seemed at first sight to depart widely from the normal type of division. The first division separated the black part of the egg from the white, and appeared to lie therefore in the position of the third plane of cleavage of the normal egg. As shown in Fig. 10 the first plane of cleavage extended between the white and black parts of the egg, beginning at the upper edge of the black. Possibly these eggs were not free to rotate in their membranes, and consequently a rearrangement of the contents of the egg took place beneath the surface. This view is supported by the fact that the following sequence of the divisions is as in the normal egg. The second furrows came in at right angles to the first, Fig. 11. The third furrows, in the few cases that were observed, cut off four upper smaller cells, two of which were dark and two light, Fig. 12. Thus the divisions are, as $I$ have said, the same as in the normal egg, although the distribution of black and white is different. The results resemble those that PFLÜGER obtained when he forcibly held eggs in oblique positions. The medullary plate when it appeared was markedly lighter than in the normal egg; which may be due, in part, to the lack of pigment in the egg itself, and also, as in PFLÜGER's eggs, to the rotation of the interior.

Some of the embryos were killed at the time when the dorsal lip of the blastopore first appeared; others at the time when the 
medullary folds were just outlined on the surface of the egg, and others when the medullary folds had closed and the tail-knobs were just beginning to form.

It was by no means an easy matter to decide in all cases whether the small eggs produced the full (normal) number of cells, which would therefore be smaller, or only half as many cells of the same size as the normal. The difficulty arises mainly from the irregular form of the cells of the embryo and from the uncertainty in locating exactly similar regions of the two embryos. For these reasons the following results are not as final as I had hoped that they might be.

It was found that the cells that make up the roof of the segmentation cavity, at the time when the dorsal lip of the blastopore has just appeared, are smaller in the dwarf embryo than in the fullsized embryo. There is also a considerable and well-marked difference in the size of the yolk-cells. The roof of the segmentation cavity is also narrower in the small embryos. In some of the pairs the difference in the size of the cells of the roof of the segmentation cavity is so slight that it does not appear to be as great as was the original difference in size between the eggs themselves, but this is a point most difficult to determine.

At the time when the blastopore finally closes the ectoderm cells of the medullary plate and the underlying mesoderm and endoderm cells are smaller in the dwarf embryos and the yolk-cells of the yolk-mass are very decidedly smaller.

In older embryos I have found it difficult, owing to the small size of the cells, to make out any decided difference, but I have no reason to suppose that the conditions here are different from the preceeding, ouly that as the cells get smaller the difference in size is harder to detect.

From these observations, that need not be given in extenso, it appears that the smaller eggs produce smaller cells. The evidence is not sufficient to establish, however plausible it may appear, that the cells are proportionately smaller. In fact, the evidence, as far as it goes, rather indicates that the cells stand somewhere between the normal and the proportionately reduced size.

The same theoretical question that is here involved I have already considered from two other points of view. I compared the size of the cells of a half-embryo of the sea-urchin, that had developed from one of the first two blastomeres, with the size of the cells of 
The Relation Between Normal and Abnormal Development etc. III. 525

the normal embryo, and found that the half-embryo is made up of cells of the same size as those in the normal, whole embryo. There are, therefore, only half as many cells in the half-embryo and these are, in comparison with the normal embryo, twice too large.

In the second place I discovered that there is a definite relation between the number of times that the segmentation nucleus divides and the size of the piece of protoplasm in which it is contained. The eggs were shaken into pieces, after they had been fertilized, and the development of pieces of different sizes was followed. It was found that the number of times that the segmentation nucleus (and its products) divide is strictly determined by the size of the piece - the larger the piece the greater the number of times it divides. I also observed that even at the two-cell stage of a fertilized fragment the new nucleus in each blastomere is smaller than the nucleus of one of the first two blastomeres of the normal egg. In other words, the size of the nucleus is influenced by the size of the cell in which it is contained, even when the number of chromosomes remains the same. This relation has often been observed and commented upon by workers in the field of cell-lineage, but the experimental proof shows that this relation is not a regulation that is peculiar to the kind of division that is taking place, was might be claimed for the cases of normal cleavage, but is due directly to a regulation between the amount of protoplasm and its contained nucleus.

Comparing these results from the sea-urchin's egg with those described here for the dwarf eggs of the frog we find the following differences in the two cases. The isolated blastomere of the seaurehin divided as many times as it would have done had it remained in contact with its fellows. The number of its divisions appears to be regulated by a size-relation between the nucleus and the protoplasm around it. Both the nuclei and the cells become smaller as the cleavage proceeds, but the cells are reduced in size proportionately faster than the nuclei. At last a stage is reached when a certain fixed relation of size is attained when further division for this stage of the development comes slowly to an end. The nucleated fragment of an egg also continues to divide until the same relation is established (without having divided as many times as the whole egg divides). The cells that result are, in relation to the size of the piece, proportionately larger than those of the whole egg (although they may be actually even a little smaller). This may be connected with the reduction in size of the first formed nuclei after 
the first division. All the subsequent nuclei are smaller than those of the same divisions of the full-sized egg.

The dwarf eggs of the frog, on the other hand, produce cells smaller than the normal; i. e., they appear to be organized on a smaller scale, and tend to produce approximately the same number of cells that are present in the full-sized embryos. Whether they actually do produce as many cells, or only show a tendency in that direction, is, as I have said, difficult to decide with certainty. The outeome, however, appears to be in principle different from that in which a part (isolated blastomere or egg-fragment) develops. In the latter ease the cells are of the same size as are those of the whole egg, and are therefore proportionally larger for the size of the small embryo than are the cells in the whole embryo. In the small, dwarf egg the cells tend to become proportionally of the same size as are those of the full-sized embryo.

\section{Extreme Forms of Spina Bifida (Ring-Embryos).}

One of the most common forms of abnormal development of the frog's egg is brought about by the failure of the lips of the blastopore to unite over the yolk, which is the result of the inability of the yolk to draw inwards at the time when the blastoporic lips are ready to move forward. All stages in the extent to which this process occurs may be found in almost any series of eggs in which the yolk has become injured by one means or by another. The most extreme cases are those in which the halves of the embryo are completely separated, uniting only at the head and tail ends as described by Roux ('88), Hertwig ('92), and myself ('93). From the evidence furnished by these embryos Roux concluded that the primordium of the embryo lies around the equator of the egg, and that the material out of which the embryo is formed extends at first on each side over nearly 180 degrees of the surface of the egg. To this conclusion I have taken exception. In the first place on the grounds that the embryo itself is not more than 120 degrees in length at the time when it first appears. In the second place an important consideration in the early development of the embryo has been overlooked. During the segmentation of the egg there is a transfer downwards of material around the sides of the upper hemisphere which is due, in part at least, to the enlargement of the segmentation cavity. There is also an extensive differentiation at the sides lead- 
ing to the formation of ectoderm and of mesoderm below the equator of the egg. If either the downward transfer of material, or the later differentiation downwards of the ectoderm and mesoderm is prevented or delayed the embryo may appear higher up on the egg, - developing presumably, in part at least, out of the same material from which the normal embryo develops. Hence the position of these ring-embryos on the egg is not a safe criterion as to the position of the material of the normal embryo before the time that the medullary plate develops. If, however, we assume that the transportation of material downwards during the cleavage, and also the formation of embryonic material below the equator, is interferred with, we can explain how it is that the ring-embryos may actually appear above the equator of the egg.

Another question of interest in this connection is whether the material of the sides, when it is as widely separated as in these ring-embryos, may not form more than half an embryo on each side. I have shown, in fact, that when one side of the egg is seriously injured the other side may produce more than a half structure. In looking over a number of egg that had been rotated in a centrifugal machine (at the rate of 170 to 200 revolutions per minute, and at a distance from the axis of rotation of from 5 to 20 inches) I found the two embryos drawn in Figs. 18-20, 19-21, in which in surface view, as seen in these figures, it appears as though possibly more than a half of an embryo lies along each side of the exposed yolk. These embryos were examined by means of sections, and although it turned out that each side is not a whole structure, as the surface views might seem to indicate, yet some other peculiarities were observed that make it worth while, I think, to give a somewhat detailed description of the two cases. I have already described a number of embryos from the centrifugal machine, none of which were as extreme forms of spina bifida embryos as these. On the other hand I have obtained as extreme forms as these in saltsolutions, and even in bunches of eggs insufficiently supplied with oxygen.

The more extreme of these two embryos is shown in Figs. 17, 18,20 . The yolk portion of the eggs, when turned upwards as in Fig. 18, is surrounded by a thickened black border. This is the medullary plate with a groove along its upper surface. It is owing to this groove that each side has the appearance, in surface view, of forming a small, but whole medullary plate. There is another 
deeper groove, just within the border of the yolk, which sections show is the beginning of the archenteron of the sides. At the posterior end of the embryo the grooves of the sides come together, and a rather wide and deep pit is formed in this region.

This embryo was cut into cross-sections. Sections taken at any point in the middle region of the embryo are like the one drawn in Fig. $A$. In this it is seen that the yolk is exposed over a broad area between the two halves of the half medullary plates. The outer edge of the yolk just inside of the medullary plates dips downwards to form a rather deep groove, the archenteron. Outside of the groove there are a few meso-endoderm cells which are continuous with the ectoderm of the medullary plate. No notochord could be found in any of the sections. The mesoderm is a broad band lying between the yolk and the ectoderm.

Towards the posterior end the yolk-mass sinks down in the middle, the archenteric grooves at the sides become deeper; and still further back they extend across the middle line, as the yolk mass sinks down, and form here the deep groove seen on the surface. The two half, mednllary plates meet behind this region. It is evident in this embryo that the halves are separated throughout their whole length, and that a whole medullary plate is not formed on each side as the surface view seemed to show.

It would be erroneous to conclude from embryos of this sort, as $I$ have pointed out above, that in the normal embryo the medullary plate is formed ont of material that is separated throughout its entire length, or that the halves of the embryo encircle as great an area of the surface of the egg as in this ring-embryo. Owing to the change in shape of this embryo its medullary folds appear longer than when first laid down. It is more difficult to account for the shortening of the anterior part of the medullary plate in this embryo (and this is a characteristic shown to a greater or less degree by all ring-embryos). The peculiarity is due, I think, most probably to the fact that the dorsal lip of the blastopore appears higher up on the egg than in the normal embryo, and this, in turn, is the result of the lack of downgrowth of material, as already described. In consequence much of the region out of which the head of the normal embryo is formed is not present in front of the dorsal lip of the blastopore, and as a result the anterior end is correspondingly shortened, although the sides of the embryo may be even longer than the normal. In a sense the material that forms part of the 
sides may represent, to some extent, material that in the normal embryo would become part of the head region, but only to a limited extent.

The other embryo has a smaller exposure of yolk, which is due largely to the advance of the ventral lip. In other respects the surface view resembles that of the last embryo. The cross-sections present several points of interest. A section through the anterior end of the medullary plate, where the sides have just come together, is represented in Fig. $B$. The medullary plate bends in here, and on one side the optic vesicle pushes out towards the surface. On the other side of this section there is a hollow ingrowth of the surface ectoderm that represents the blastema of the right ear, and a few sections further back the blastema of the left ear is present (the sections being cat somewhat obliquely). In sections further forward I can not identify any thickenings to form the lenses of the eyes. The infundibular ingrowth of ectoderm is well developed in these anterior sections. A few sections further back than the one here figured show the halves of the medullary plate drawing apart, and the notochord appearing on each side, as in Fig. $C$. Towards the posterior end of the embryo, Fig. $F$, the lateral grooves of the archenteron become deeper, the yolk projects less and finally the sides of the embryo come together across the middle line. The half medullary plates, that have become smaller, meet, and posterior to this region the deep groove seen on the surface is indicated by a depression of the ectoderm, Fig. $D$. In this region the mesoderm from the sides also meets across, and there is present a small archenteron in the yolk that opens out more anteriorly on the surface. A few sections further back, the surface groove deepens and then unites with the posterior extension of the archenteron, as shown in Fig. $E$. This opening is the anus. What appears to have happened in this posterior region is this: - A posterior backgrowth of the archenteron under the ventral lip has taken place. The sides of the ventral lip have grown forward and have met above the yolk, the groove on the surface indicating their line of union. Whether a posterior opening has remained behind, or a new one has formed cannot be determined at so late a stage. The groove on the surface can not be interpreted as equivalent to the very small groove in the normal embryo that appears behind the blastopore, after the blastopore, which remains for a time as the neurenteric canal, has become reduced to a small opening. The anus is formed, it is true, at the posterior end of the groove in the normal embryo as a new opening; but there 
was left no groove on the surface as the ventral lip advanced. In the abnormal embryo the large depression on the surface represents the line along which a fusion of the posterior sides of the embryo have united over the surface of the yolk and not the groove of the normal embryo behind the neurenteric canal.

ZiEgLer in his recent, "Lehrbuch der vergleichenden Entwickelungsgeschichte der niederen Wirbelthiere « describes the normal process of closure of the blastopore of the frog as taking place in the following way: - When the last trace of the yolk-plug has disappeared within the small blastopore the lateral lips of the blastopore come together and fuse, leaving the anterior end open as the neurenteric canal and the posterior end as the anus. The dark groove seen on the surface represents the line of union of the lateral lips. 'This description is erroneous for the frog, although it is exactly what takes place, as I have shown, for Amblystoma. I have examined a great number of sections through frog embryos at the time when the blastopore is overarched by the medullary folds, and find that when the neurenteric canal is just overarched (it is the only part of the blastopore that is left open after the yolk-plug has been withdrawn) and the anus has not broken through, the archenteron has no posterior opening. This could not be the case if ZIEGLER's description is correct. Moreover an examination of the relation of the anus to the archenteron will show that ZIEGLER's description must be wrong, for the anus opens at the posterior end of a posterior saclike extension of the archenteron which lies some distance behind the first position of the blastopore. In 1889 I described this mode of development, and since then I have re-examined the same preparations and new ones also, and find my account entirely correct. Schayz had in 1887 given an exactly similar description of the closure of the blastopore which account by an unfortunate oversight I failed to see, and did not refer to in my paper. My results have, therefore, at least the value of independent observations, although the credit for first giving an exact account of what takes place belongs to Schaxz. The ventral lip moves forward over the region in which the anus will form, and, in fact, helps to form the posterior pocket of the archenteron, (which is probably deepened also by the pulling in of the yolk-cells in this region). The anus is a new invagination, and the little groove on the surface is also new, although I will not deny that the groove may sometimes be faintly marked as the blastopore undergoes the final stages of its closure. 
To return to the abnormal embryo represented in Figs. 18 and 19. I have pointed out that the anterior single portion of the mednllary plate is very short, and yet the optic vesicles are present at its anterior end, and the infundibulum turns in just in front of the termination of the plate. It is evident, therefore, that this part must really represent the anterior end of the fore-brain. It will also be noticed that the two ears lic almost at the level of the optic vesicles, and are therefore very far forward as compared with the optic vesicles. This supports strongly the point that I have tried to make above, namely, that the brain region is very much shortened in these embryos. I have further interpreted this to mean that there has not taken place the normal, downgrowth of material from which the anterior part of the medullary plate develops in the normal embryo.

\section{Summary.}

1) The eggs of the frog in which the first furrow divides the material as unequally as in Figs. 1 and 3 may give rise to a normal embryo.

Irregular division like that shown in Figs. 6 and 7 and in Figs. 8 and 9 is probably due to polyspermy.

An analysis of the results published by Morgan and Boring ${ }^{1}$ ) suggests the hypothesis that those exceptional cases $(81 / 2$ per cent) in which the first plane of cleavage is at right angles to the median plane of the gray area, are due to a secondary rotation of the contents of the egg that carries the spindle into a new position. The median plane of the embryo of the frog appears to be established by the plane of symmetry in the protoplasm, and may coincide in these cases either with the first plane of cleavage or with the median plane of the gray crescent according to which influence predominates; i. e., according to which plane of symmetry is the more potent.

The position of the spindle in the cell appears to be determined by movements of the protoplasm, and these in turn may be the result of different internal and external conditions. It is improbable that the cause of the protoplasmic movements is the same for all kinds of cells.

2) The evidence in favour of the view that gravity determines the position of the gray area, and hence of the median plane of the

1) This Archiv. XVI. 1903. 
embryo of the frog, does not preclude the possibility that if gravity is removed, as in KathaRINER's ('03) and in my own experiments ('03), the embryo may have its median plane determined by some other factors.

3) The half embryo represented in Fig. 26 was obtained by sticking with a hot needle one of the first two blastomeres before the first furrow had completed itself. The method of formation of an embryo of this kind, (see cross-sections $G, H, I$ ), is illustrated by the diagrams shown in Figs. 13, 14, 15. The head of the embryo is nearly a whole structure and this is not due to a half head being first laid down which then completes itself on the inner side, but the head is from the beginning laid down nearly symmetrically in the material in front of the first position of the dorsal lip of the blastopore.

An analysis of the conditions present when a half-embryo develops leads to the view that when such a half-embryo is first formed the uninjured material of the other side can not be used to produce the missing half, unless it has also first gone through the regular process of gastrulation at the time when the uninjured half has gastrulated.

4) Dwarf eggs of the frog are sometimes found whose volume may be no greater than half that of the normal egg. These dwarf eggs correspond, therefore, in volume to one of the first two blastomeres. They give rise to normal dwarf-embryos. The cells in these dwarf-embryos are smaller than those in full-sized embryos, indicating that the small eggs tend to pass through the same number of divisions as does the normal egg. The isolated blastomere of the sea-urchin's eggs on the contrary produces only half as many cells as does the whole egg.

5) Extreme forms of spina bifida, - ring-embryos - , show that the medullary plate may be divided to nearly its anterior end. It would be erroneous to conclude from this condition that in the normal embryo the dorsal lip of the blastopore begins near the anterior end of the brain and that the rest of the embryo is formed by concrescence. The difference in the two cases can be accounted for on the assumption that in the ring-embryos the downgrowth of material during the late cleavage-stages, which takes place in the normal egg, fails to occur, and in consequence the embryo develops higher up on the egg.

Bryn Mawr College, March 21, 1904. 
The Relation Between Normal and Abnormal Development etc. III. 533

\section{Zusammenfassung.}

1) Die Froscheier, bei denen die erste Furche das Material so ungleich teilt, wie Fig. 1 and 3 zeigen, können einem normalen Embryo zum Ursprung dienen.

Unregelmäßige Teilung, wie in Fig. 6 und 7 und in Fig. 8 und 9, beruht wohl auf Polyspermie.

Eine Analyse der Resultate von Morgan and Boring führt zu der Hypothese, daß die ausnahmsweisen Fälle (etwa $81 / 2 \%$, in welchen die erste Teilungsebene rechtwinklig zur Mittelebene des grauen Feldes steht, auf einer sekundären Rotation des Eiinhalts beruht, welche die Spindel in eine neue Lage bringt. Die Medianebene des Froschembryos scheint durch die Symmetrieebene im Protoplasma im voraus gegeben zu sein und kann in diesen Fällen entweder mit der ersten Furchungsebene oder mit der Medianebene des grauen Feldes zusammenfallen, je nachdem der eine oder andre Einfluß der stärkere ist, d. h. je nach der größeren Potenz der einen oder der andern Symmetrieebene.

Die Stellung der Spindel in der Zelle scheint durch Protoplasmabewegungen bestimmt zu werden, und diese können wiederum das Ergebnis verschiedener innerer und äußerer Bedingungen sein. Es ist unwahrscheinlich, daß die Ursache der Protoplasmabewegungen für alle Arten von Zellen dieselbe ist.

2) Die augenscheinlichen Beweise zugunsten der Annahme, daß die Schwerkraft die Lage des grauen Feldes bestimmt und somit auch die Lage der Medianebene des Froschembryos, schließt die Möglichkeit nicht aus, daß nach Ausschaltung der Schwerkraft (wie bei Kathariner [1903] und meinen eignen Versuchen [1903]) die Medianebene des Embryos durch einige andre Faktoren bestimmt werden kann.

3) Die in Fig. 16 abgebildeten Halbembryonen wurden durch Anstechen einer der beiden ersten Blastomeren vor Vollendung der ersten Furche erhalten. Die Diagramme Fig. 13, 14, 15 zeigen die Bildungsweise eines derartigen Embryo Querschnitte $G, H, I$ ). Der Kopf des Embryo ist nahezu eine Ganzbildung, die nicht etwa durch nachtrigliche Komplettierung einer ursprünglich halben Kopfanlage an deren medialer Seite zustande kam, vielmehr wurde der Kopf von Anfang an nahezu symmetrisch in dem nach vorn von dér ersten Lage der dorsalen Blastoporuslippe gelegenen Material angelegt.

Eine Analyse der die Entstehung eines Halbembryo beherrschenden Bedingungen fuihrt zu der Ansicht, daß, wenn ein solcher Halbembryo zuerst gebildet wird, das unbeschädigte Material der andern Seite nicht zur Hervorbringung der fehlenden Hälfte verwendet werden kann, ohne daß es gleichfalls zuerst den regulären Gastrulationsproze $\beta$ zu der Zeit durchlaufen hat, in der die unverletzte Hälfte gastruliert hat.

4) Bisweilen findet man Zwergeier beim Frosch, deren Volumen nicht größer sein kann als das halbe der normalen Eier. Das Volumen dieser Zwergeier entspricht also dem von einer der beiden ersten Blastomeren. Aus ihnen entstehen normale Zwergembryonen. Die Zellen in diesen Zwergembryonen sind kleiner als die in Embryonen ganzer Größe, ein Anzeichen, daß die kleinen Eier dieselbe Anzahl von Teilungen zu durchlaufen haben, wie die normalen Eier. Die isolierte Blastomere der Seeigeleier produziert dagegen nur halb so viele Zellen, wie das ganze Ei. 
534 T. H. Morgan, The Relation Between Normal and Abnorm. Developm. etc. III.

5) Extreme Formen von Spina bifida - Ringembryonen - zeigen, daß die Medullarplatte bis nahe an ihr vorderes Ende geteilt sein kann. Es würde ein Trugschluß sein, deshalb anzunehmen, daß im normalen Embryo die dorsale Blastoporuslippe nahe am vorderen Ende des Gehirns beginnt und daß der Rest des Embryo durch Concrescenz entsteht. Dem Unterschied der beiden Fälle kann durch die Annahme Rechnung getragen werden, da $\beta$ bei den Ringembryonen das Herabwachsen des Materials in den letzten Furchungsstadien ausfällt, welches bei normalen Eiern stattfindet, so daß bei jenen der Embryo höher oben am Ei sich entwickelt. 